\title{
Design of the Power Supply System for Vertical Take-Off and Landing Unmanned Aerial Vehicle
}

\author{
Jakub CZECH ${ }^{1}$ and Wojciech SKARKA ${ }^{2}$ \\ Silesian University of Technology, Faculty of Mechanical \\ Engineering, Poland
}

\begin{abstract}
The article presents an analysis of the possibilities of supporting the Vertical Take off and Landing Unmanned Aerial Vehicle electric power systems by using photovoltaic cells. A typical commercial VTOL class drone with electric power was selected for analysis. Concepts of power supply supported by photovoltaic cells have been developed. Analysis of the potential change in performance through the use of such support are presented on the basis of the UAV simulation model and the model-based design. The simulation model takes into account not only the flight parameters of the drone, but also the drive system with the power supply system and the assumed variable lighting parameters. Such a multidisciplinary model was used to analyse the functional parameters. The analysis also includes hypothetical changes in the performance parameters of photovoltaic cells and their impact on the change in UAV performance as well as the impact of changes in the airframe geometry on the profitability of using such a solution.
\end{abstract}

Keywords. VTOL UAV, photovoltaic cells. Model-Based Design, simulation model, power supply, aircraft design

\section{Introduction}

Nowadays, the electric drives are displacing the internal combustion drives, due to its flexibility, resistance to thermal changes, and possibility of using renewable energy sources. Thanks to that we can reduce exhaust fumes and pollution, which are harmful to environment. Taking into account advantages of photovoltaics cells e.g. its durability, increasing efficiency and easy connection to others devices (batteries, capacitors) solar cells shows great potential in application for autonomous vehicles. In this specific case some extraordinary factors must be considered (e.g. cloudy, temperature, irradiance). Various aspects are touched upon in this work beginning with UAV design, by analyzing weather conditions, all the way to electrical engineering and its issues such as converters and elements of the electrical circuit. Main goal of this work is to give an answer to question whether solar-powered UAV is reasonable.

\footnotetext{
1 just.czechu@gmail.com

${ }^{2}$ wojciech.skarka@polsl.pl
} 


\section{Division of vertical take-off and landing vehicles}

To begin the conceptual process formation of UAV VTOL we must first consider which structure will bring the optimal ratio of hovering and surface to place their solar cells, with possibly the best mounting angle to reach the highest energy yield. Figure 1 presents the general division of vertical take-off and landing vehicles.

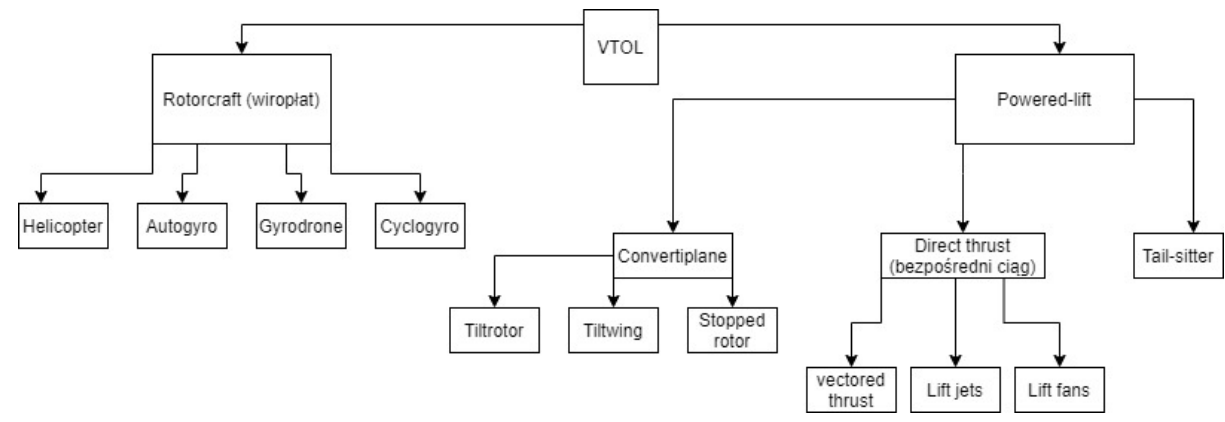

Figure 1. General division of vertical take-off and landing vehicles due to design and the type of drive

Due to the high complexity of the construction process the load-bearing structure (UAV VTOL tailsitter structure) was adopted from the "Sky X" project - its geometric dimensions. All calculations in this document are based on these assumptions. Sky-X structure and basic dimensions are shown in Figure 2. [1]

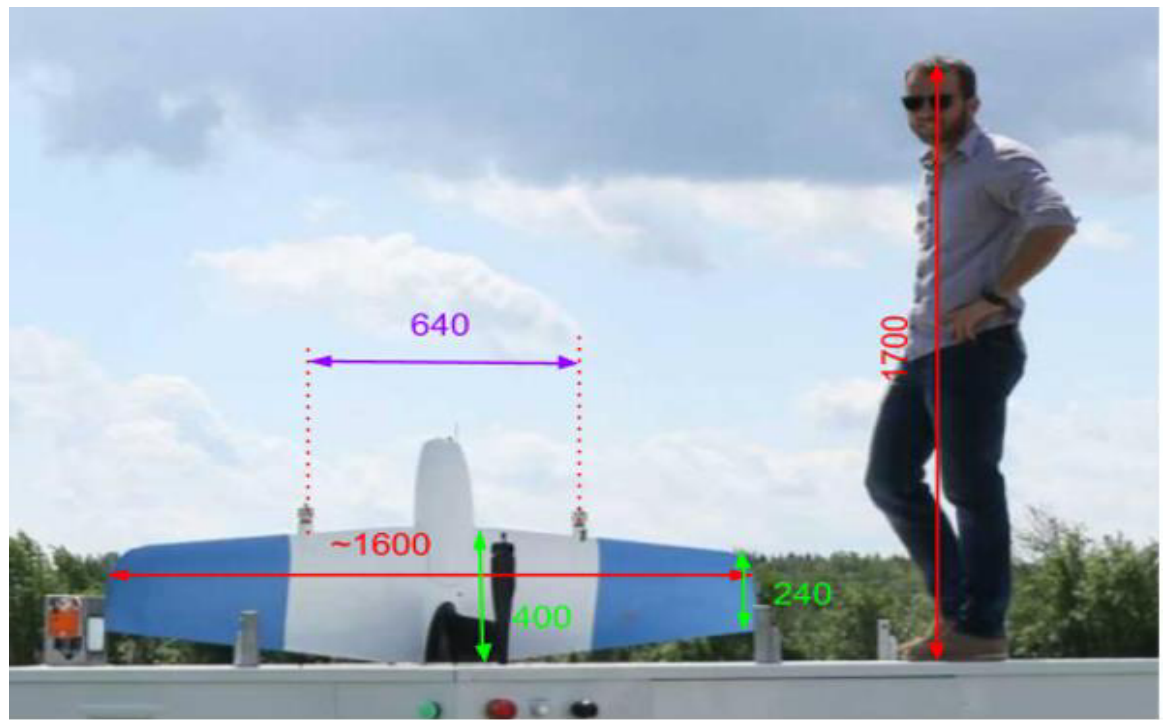

Figure 2. Sky X basic dimensions in reference to human adult.

In order to provide the best possible power, MPPT devices are used to adjust the voltage from photovoltaic cells. These are high-performance DC-DC converters with adjustable gain between the input voltage (PV cells) and the output voltage (batteries). Such a converter can also change the input voltage for other devices such as servo motors, radio, GPS or speed controllers. The figure shows a diagram of the operation of a system with PV cells, MPPT converter, batteries and other devices. Figure 3 presents concept of the power supply system, together with the UAV VTOL control system. [2][3] 

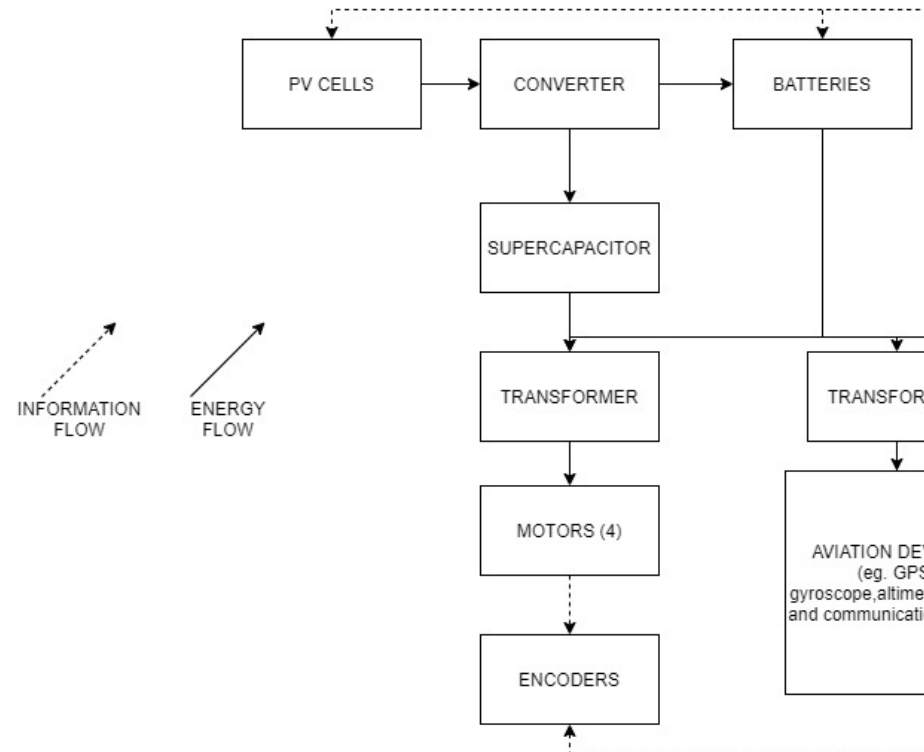

Figure 3. Power supply and control systems of vertical take-off and landing unmanned aerial vehicle taking into account both the flow of energy and information, with necessary equipment.

\section{Criteria for the selection of photovoltaic cells in terms of geometric configuration and efficiency.}

As it has been written the entire system will be powered by solar cells. It should also be remembered to appropriate selection of batteries and accumulators that will accumulate the energy generated by PV panels so that the VTOL can also fly at night (when no solar energy is available). The basic criterion that will be set for PV cells will be flexibility the goal of their highest efficiency, an equally important factor will be their weight, efficiency and the influence of temperature. After evaluation to the further calculations were chosen GaAs solar cells. Due to the conceptual nature of the work, the financial aspect may be omitted. [4]

\section{The influence of the clouds on energy performance.}

Cloud cover has a direct impact on the amount of radiation hitting the solar cell, thus determining the power that the cell can generate. Clouds may have a different structure, sky coverage, degree of water, or density and thickness, so their behaviour towards solar radiation will change. Figure 4 shows the dependence of solar radiation reaching the Earth's surface on the types of clouds and the height of the Sun.

Cloud cover has a direct impact on the amount of radiation hitting the solar cell, thus determining the power that the cell can generate. In this paper calculations were made based on publications, and then modelled with octane scale, which distinguishes 10 degrees of cloud cover from $0 / 8$ (clear sky) to $9 / 8$ (sky invisible). Thanks to that sky 
coverage can be easily divided into $10 \%$ steps. Octane scale was better descripted in bibliography sources.[5][6]

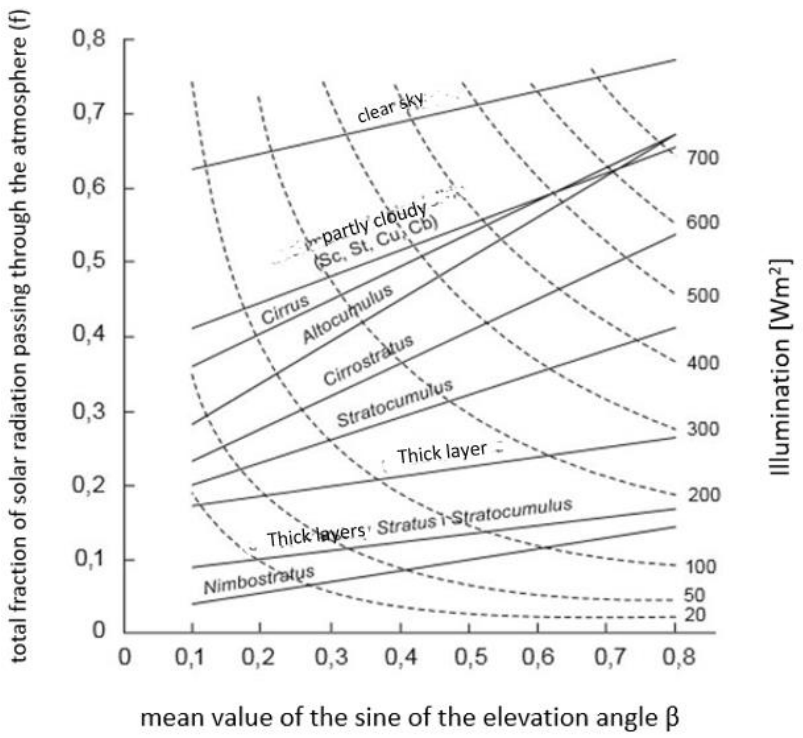

Figure 4. Dependence of solar radiation reaching the Earth's surface on the types of clouds and the height of the Sun

\section{Solar energy availability}

The amount of solar radiation available depends on several factors, the main ones being latitude, as well as the position of the sun in the sky. We can assume that during the flight UAV VTOL maintains a horizontal flight trajectory, parallel to the Earth's surface, then the intensity of solar radiation can be defined as the sum of scattered, reflected and direct components of solar radiation intensity. Availability of solar radiation was expressed in article of D. Matuszko [5] and also on paper. [9]

\section{Model-based design methods assumptions}

In order to verify the photovoltaic power supply system and its validity, specific functional tests should be carried out.

After verifying the load capacity of the UAV VTOL, the following functional tests should be performed:

- UAV vertical take-off and landing with photovoltaic panels and a battery,

- UAV vertical take-off and landing with greater battery capacity (greater number of cells).

Next step, which has to be done is to check whether the use of photovoltaic cells for a given technological problem is justified. Tests should be performed at: 
- $\quad$ variable irradiance value (e.g. cloudiness, fog, night),

- variable temperature,

- the optimal inclination of the solar cell must be taken into account for the best possible results.

\section{Developed calculation model}

In the MATLAB R2019 computing environment, specifically its Simulink software, a model of the power system was developed, consisting of a photovoltaic cell, a battery, a supercapacitor and a converter [7][8]. Calculation model is presented in figure 5.

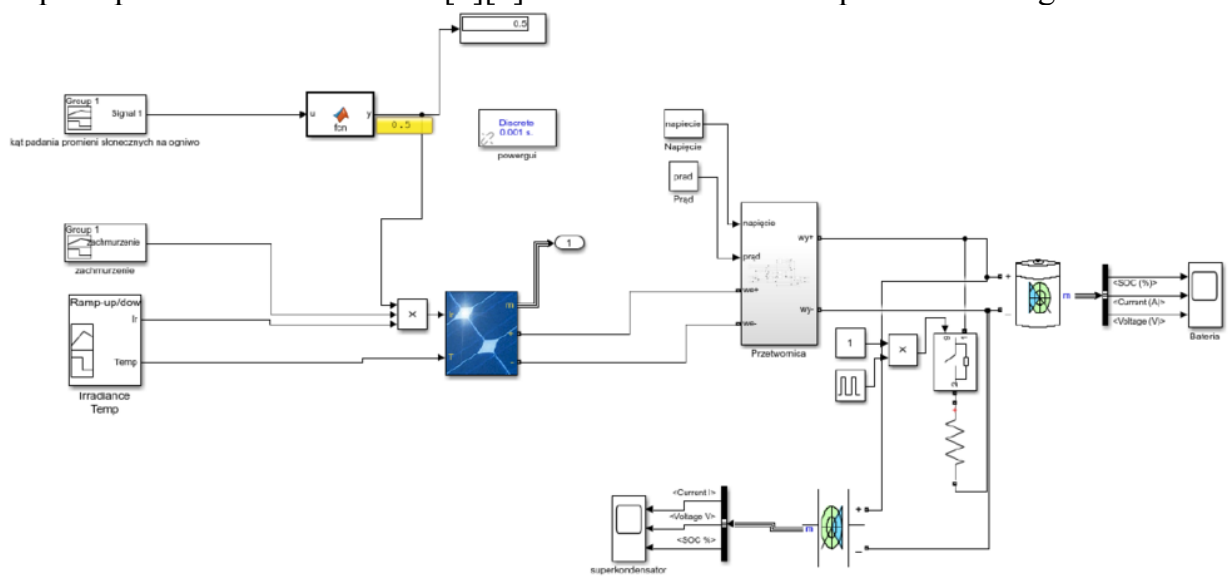

Figure 5. The entire power supply system with a photovoltaic cell and a supercapacitor.

The models available in the Simulink software library were used to develop the model shown in Figure 7. These models are mathematical representation of physical devices available on the market. With the photovoltaic cell, in order to obtain more real power yields, the following were additionally modelled:

- temperature change,

- change of insolation value,

- cloud cover,

- the angle of incidence of sunlight on the cell.

Changing the angle of incidence of sunlight on the cell affects the output power of the solar cell - in accordance with the Lambert's law. [9]

Signal, which represents the angle of sun's elevation, is featured as a triangular time function as is it often proposed in scientific studies. This angle will vary depending on the latitude or the day of the year.

The cloud cover value on a scale of $0-1$ (where 0 - cloudless sky, 1 - sky fully covered with clouds) was also modelled using a signal. Irradiance and temperatures were also modelled as a signals of value in time. [5]

The developed computational model uses the block of the photovoltaic cell function built into the Simulink environment. It was decided to use it because of a better representation of the work of a real photovoltaic cell. 
The converter is an important element of the system. The electricity generated by the solar cell is supplied further (including to the battery) via a DC-DC converter of the CC-CV type (Constant Current - Constant Voltage). Figure 6 shows the converter block with the set values of operation - voltage and current, and Figure 7 shows the inside of the converter block - its proper model which were elaborated based on the thoughts and experiences of the authors and the results of similar works. Creation and development of DC-DC converters is a frequently discussed engineering topic, which was described in many studies that inspired this work In the context of general assumpions [10], converters [11], lithium battery modelling [12] PV - battery - supercapacitors configurations [13] charging and discharging of supercapacitors [14] models of PV cells [15]

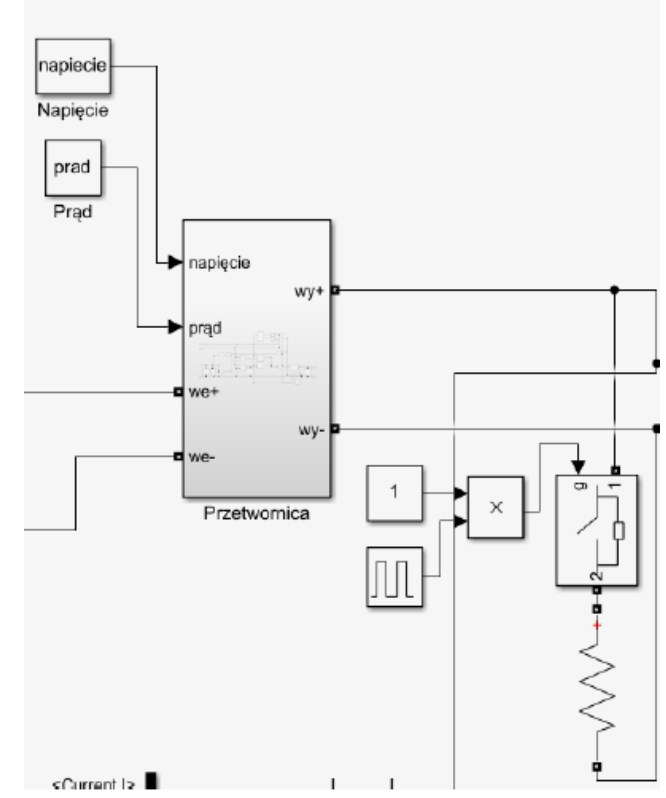

Figure 6. Blocks, which determine converter's proper work. Consist of input values of variables, which are necessary to proper work of converter so as: input voltage and current.

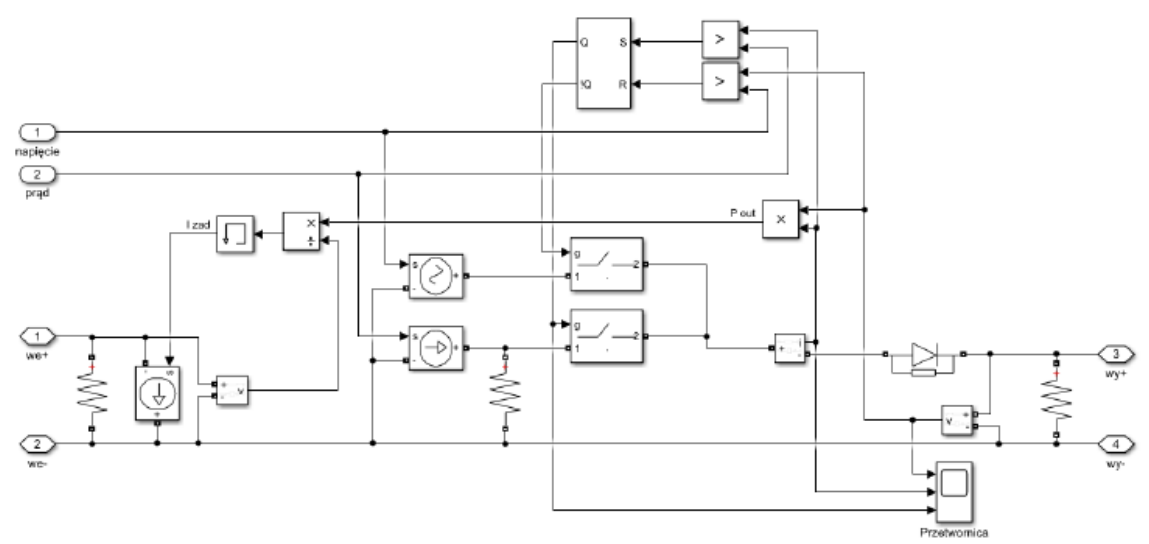

Figure 7. Modelled DC-DC converter - modelled as CC-CV converter (constant current- constant voltage). Developed model is mean value converter. 
In the developed calculation model, the li-ion battery model existing in the libraries of the MATLAB 2019R Simulink same as supercapacitor.

\section{Calculation and assumpitons of VTOL energy requirements}

Calculations were made using equations which can be found in additional scientific papers. Table consists of input values serving, together with the output results resulting from their substitution into the formulas. Calculations were prepared for 2 cases:

- Without solar panels (take-off mass)

- With solar panels (take-off mass)

Table 1 presents energy requirements for VTOL without mass of solar panels and comparatively after re-evaluation.

Table 1. VTOL energy requirements before and after re-evaluation.

\begin{tabular}{|c|c|c|c|c|}
\hline Parameter name & Symbol & $\begin{array}{l}\text { Value before re- } \\
\text { evaluation }\end{array}$ & $\begin{array}{l}\text { Value after re- } \\
\text { evaluation }\end{array}$ & Unit \\
\hline Take-off mass & Wto & 20 & 20,72 & $\mathrm{~kg}$ \\
\hline Air density & $\rho$ & 1,2 & 1,2 & $\mathrm{~kg} / \mathrm{m} 3$ \\
\hline Climb velocity & $\mathrm{Vc}$ & 6 & 6 & $\mathrm{~m} / \mathrm{s}$ \\
\hline Power coefficient & $\mathrm{k}$ & 1,2 & 1,2 & - \\
\hline Coefficient & KT & 1,15 & 1,15 & - \\
\hline Maximum established thrust & Tmax & 23 & 23,83 & $\mathrm{~N}$ \\
\hline Propeller radius & $\mathrm{Rp}$ & 0,2 & 0,2 & $\mathrm{~m}$ \\
\hline Propeller area & A & 0,1256 & 0,1256 & $\mathrm{~m} 2$ \\
\hline Propeller power & $\mathrm{P}$ & 1176,3 & 1238,8 & W \\
\hline zero wing factor & CD0 & 0,008 & 0,008 & - \\
\hline Wing area & $S$ & 0,36 & 0,36 & $\mathrm{~m} 2$ \\
\hline Thrust in climb & $\mathrm{Tc}$ & 20,0622 & 20,7822 & $\mathrm{~N}$ \\
\hline $\begin{array}{l}\text { Maximum admissible climb } \\
\text { velocity }\end{array}$ & Vmax & 24,5235 & 24,7413 & $\mathrm{~m} / \mathrm{s}$ \\
\hline Battery discharge efficiency & $\eta \mathrm{b}$ & 0,95 & 0,95 & - \\
\hline ESC efficiency & $\eta \mathrm{e}$ & 0,95 & 0,95 & - \\
\hline BLDC motors efficiency & $\eta \mathrm{m}$ & 0,9 & 0,9 & - \\
\hline Propeller power in climb & $\mathrm{Pc}$ & 963,4 & 1014,3 & W \\
\hline Altitude (established) & $\mathrm{Hm}$ & 1000 & 1000 & $\mathrm{~m}$ \\
\hline $\begin{array}{l}\text { Total energy consumption in } \\
\text { climb }\end{array}$ & $\mathrm{Ec}$ & 395378,2 & 416262,3 & $\mathrm{Wh}$ \\
\hline Velocity in horizontal flight & $\mathrm{Vr}$ & 33,7 & 34,3 & $\mathrm{~m} / \mathrm{s}$ \\
\hline Velocity in horizontal flight & $\mathrm{Ve}$ & 25,6 & 26,0 & $\mathrm{~m} / \mathrm{s}$ \\
\hline
\end{tabular}




\begin{tabular}{lllll}
\hline Parameter name & Symbol & $\begin{array}{l}\text { Value before re- } \\
\text { evaluation }\end{array}$ & $\begin{array}{l}\text { Value after re- } \\
\text { evaluation }\end{array}$ & Unit \\
\hline Thrust in horizontal flight & $\mathrm{Tr}$ & 3,9 & 4,1 & $\mathrm{~N}$ \\
\hline Thrust in horizontal flight & $\mathrm{Te}$ & 4,5 & 4,7 & $\mathrm{~N}$ \\
\hline Propeller power & $\mathrm{Pr}$ & 160,2 & 168,9 & $\mathrm{~W}$ \\
\hline Propeller power & $\mathrm{Pe}$ & 142,1 & 149,8 & $\mathrm{~W}$ \\
\hline Energy consumption & $\mathrm{Ecr}$ & 11711,4 & 12133,1 & $\mathrm{Wh}$ \\
\hline Energy consumption & $\mathrm{Ece}$ & 13671,4 & 14163,6 & $\mathrm{Wh}$ \\
\hline
\end{tabular}

\section{Analysis of energy yields}

Two cases were taken into account: the first - the longest day of the year and the second - the shortest. For both described cases it was assumed that there is no cloud cover - the sky is clear and the entire solar radiation intensity falls on the surface of the photovoltaic panels. Only the decrease in energy yields is taken into account, in line with Lambert's law. The value of solar radiation intensity is taken into account, similarly to other calculation models, for similar technological solutions as the value of solar intensity occurring for the equator at solar noon, i.e. $1200 \mathrm{~W} / \mathrm{m} 2$. The area of the wings (including the area of solar panels located on them) is $0.72 \mathrm{~m} 2$. GaAs cells parameters (made of gallium arsenic) were used for the calculations. Such cells are characterized by a low weight (100 $\mathrm{mg} / \mathrm{cm} 2=1 \mathrm{~kg} / \mathrm{m} 2$ ), as well as a high efficiency of $28 \%$ (in some studies, a higher value is given, but most studies indicate the value of $28 \%$ ). Then, the values presented in Table 1 were revalued, taking into account the increased weight of the entire structure due to the presence of photovoltaic panels. Table 2 presents input values, used in calculations and table 1 presents energy requirements for VTOL with solar panels (column value after re-evaluation).

Table 2. Input values.

\begin{tabular}{lll}
\hline Irradiance value $[\mathbf{W} / \mathbf{m} 2]$ & Solar panels area $[\mathbf{m} 2]$ & Panels efficiency $[\%]$ \\
\hline 1200 & 0,72 & 28 \\
\hline
\end{tabular}

Then, the possible energy yields (Table 3) resulting from the use of GaAs photovoltaic cells on the ship's surface on the longest and the shortest day of the year, respectively, were calculated. No cloudiness was assumed, as well as a constant value of solar radiation intensity, similar to other studies, such as on the equator at solar noon $(1200 \mathrm{~W} / \mathrm{m} 2)$.

Table 3. Possible solar yields.

\begin{tabular}{ll}
\hline Season & Solar yields [W] \\
\hline For the longest day of the year & $1862,784 \mathrm{~W}$ \\
\hline For the shortest day of the year & $895,104 \mathrm{~W}$ \\
\hline
\end{tabular}

The increased WTO take-off weight is of particular importance in the vertical flight phase. Increasing this mass by $0.72 \mathrm{~kg}$ resulted in an increase in energy consumption by 
as much as $20,884.11 \mathrm{Wh}$, and in the horizontal flight phase by 421.61 and 492.17 [Wh] respectively. [17][18]

\section{Conclusions}

Due to the gradual withdrawal from conventional energy sources known to mankind, such as coal or fossil fuels, alternative sources of electricity should be sought, preferably renewable, obtained from natural sources and not affecting the natural environment. The paper analyses the possibility of developing a power supply system for vertical take-off and landing unmanned aerial vehicles. For such a technical solution, the cells are required to exhibit appropriate parameters, such as:

- $\quad$ appropriate weight,

- flexibility,

- high efficiency.

After analysing the photovoltaic cells available in scientific studies, it was decided to accept cells made of gallium arsenic (GaAs) for further analysis. Such cells have the best weight-to-efficiency ratio among the currently developed and analysed photovoltaic cells. Their weight is $100 \mathrm{~g} / \mathrm{cm} 2$, and the efficiency reaches even $28 \%$, which suggested that the use of this type of cells would be completely justified. Due to the conceptual nature of the work, the financial value of such a solution was omitted.

In further analysis, calculations were made to estimate the energy requirements of UAS. It was found that the best type of such vessel that could be powered by solar energy would be a tail sitter, which carries out the ascent and landing process vertically, and then, after reaching the assumed cruising altitude, goes to level flight. The dimensions of the "SKY X" aircraft, which is a commercial tail sitter solution, were adopted for the calculations. Then, with the assumed dimensions, calculations were carried out with the use of MS Office Excel environment, thanks to which the energy consumption values were calculated in the phase of vertical and horizontal flight. In the next step, the same values were calculated for the increased initial weight of the WTO, which was increased by the weight of the photovoltaic cells used. Possible energy yields resulting from the use of photovoltaic cells with $28 \%$ efficiency on days with the longest and the shortest number of sunny hours were also calculated. After comparing these values, we can conclude that the use of currently available technologies photovoltaics in aircraft that carry out missions on a surface not exceeding the stratosphere are unjustified, because the yields from such cells will not be able to compensate for the energy expenditure that is necessary for the performance of cruise missions by aircraft of vertical take-off and landing. Although the values of the yields were approximate, the analysis assumed that there was no cloud cover (thus the solar radiation intensity was not dispersed), and the effect of the wind force was not taken into account, which could also affect the resulting power. It was also assumed that the panels are arranged on the surface in such a way as to maximize the energy yield that the PV panel can provide. The analysis includes the variable efficiency of cells resulting from the occurrence of Lambert's law, which concerns the efficiency of the resulting panels.

In order to use solar cells in such a technical issue as an unmanned aerial vehicle for vertical take-off and landing, it would be necessary to develop photovoltaic panels, the efficiency of which would be significantly improved compared to those available so far. 
A lot of hope are perovskites - naturally occurring minerals that can absorb sunlight (e.g. calcium titanium), but the naturally occurring ones do not conduct electricity. However, modified in the laboratory, they gain new features, such as current conductivity. At the moment, the perovskites are efficient at the level of 20-25\%. However, in the future they can feature in many energy-renewable solutions.

\section{References}

[1] https://skyx.com/ Accessed: 01.03.2021

[2] J. G. Leishman, Principles of Helicopter Aerodynamics, Cambridge University Press, New York, 2006.

[3] J. D. Anderson, Aircraft Performance and Design, WCB/ McGraw-Hill, Bethesda, 1999.

[4] W. Zientarski, R. Figura, Analysis of the operating parameters of the photovoltaic module, Buses (in polish: Analiza parametrów pracy modułu fotowoltaicznego, Autobusy) 12/2016, s.602-611, 2016.

[5] D. Matuszko, The influence of cloudiness on insolation and total solar radiation, (in polish:Wpływ zachmurzenia na usłonecznienie i całkowite promieniowanie słoneczne), Wydawnictwo Uniwersytetu Jagiellońskiego, Kraków, 2009.

[6] J.R.L. Monteith, Physics of the biological environment (in polish: Fizyka środowiska biologicznego), PWN, Warszawa 1979.

[7] K. Mateja, W. Skarka, Towards energetic autonomy of UAV. Advances in Transdisciplinary Engineering, Vol. 12, pp. 423-432.

[8] R. Niestrój, T. Rogala, W. Skarka, An Energy Consumption Model for Designing an AGV Energy Storage System with a PEMFC Stack, Energies, 2020, 13(13), 3435.

[9] S. Chukwuebuka Arum, D. Grace, P.D. Mitchell, M.D. Zakaria, N. Morozs, Energy Management of Solar-Powered Aircraft-Based High Altitude Platform for Wireless Communications, Electronics, 2020, 9(1), 179.

[10] H. Zhongxi, W. Bo, L. Zhaowei, C. Qingyang, Z. Xiongfeng, Preliminary Design of a Small Unmanned Battery Powered Tailsitter, International Journal of Aerospace Engineering, 2016, 3570581 .

[11] N. Hinlov, Generalized Models of Basic DC-DC Converters, AIP Conference Proceedings, 2018, 2048, 060021.

[12] M. Benes, R. Fucik, V. Havlena, V. Klement, M. Kolar, O. Polivka, J. Solovsky, P. Strachota, An Efficient and Robust Numerical Solution of the Full-Order Multiscale Model of Lithium-Ion Battery, Mathematical Problems in Engineering, 2018, 3530975.

[13] M.E. Sahin, F. Blaabjerg, A Hybrid PV-Battery/Supercapacitor System and a Basic Active Power Control Proposal in MATLAB/Simulink, Electronics, 2020, 9(1), 129.

[14] S. Allu, B. Velamur Asokan, W.A. Shelton, B. Philip, S. Pannala, A generalized multi-dimensional mathematical model for charging and discharging processes in a supercapacitor, Journal of Power Sources, 2014, Vol. 256, pp. 369-382.

[15] W. Abd El-Basit, A.M. Abd El-Maskood, F.A. Soliman, Mathematical Model for Photovoltaic Cells, Leonardo Journal of Sciences, 2013, Issue 23, pp. 13-28.

[16] R.H. Stone, The T-wing tail-sitter unmanned air vehicle: from design concept to research flight vehicle, Proceedings of the Institution of Mechanical Engineers, Part G: Journal of Aerospace Engineering, 2004, Vol. 218, No. 6, pp. 417-433.

[17] U. Ozdemir, Y.O. Aktas, A. Vuruskan, Y. Dereli, A.F. Tarhan, K. Demirbag, A. Erdem, G.D. Kalaycioglu, I. Ozkol, G. Inalhan, Design of a commercial hybrid VTOL UAV system, Journal of Intelligent \& Robotic Systems, 2014, Vol. 74, pp. 371-393.

[18] R. Mozo Ordóñez, Diseño de las alas de un vehículo aéreo no tripulado (UAV), Universidad De Valladoid Escudela De Ingenierias Industriales, Valladoid, 2017.

[19] A.V. Welles, Hybrid Electric Distributed Propulsion for Vertical Takeoff and Landing Aircraft, Syracuse University, 2018. 